\title{
Decision Support Systems for the Forest Insect and Disease Survey and for Pest Management ${ }^{1}$
}

by

\author{
J.M. Power ${ }^{2}$
}

\begin{abstract}
Effective forest pest management involves decision-making supported by useful information. The concept of Decision Support Systems is being actively pursued by the Forest Insect and Disease Survey (FIDS) of the Canadian Forestry Service to meet its information needs for analysis of forest pest conditions. The FIDSINFOBASE system was developed to provide FIDS units nationwide access to survey data. Geographic Information System capabilities are being integrated for capture and analysis of infestation maps. Possibilities exist for the integration of systems, data, and models among agencies for information standardization and exchange.
\end{abstract}

Key words: information systems, forest pest management, insect and disease surveys.

\section{Résumé}

Une gestion efficace des ravageurs forestiers suppose une prise de décisions basée sur l'information pertinente. La Direction du Relevé des insectes et des maladies des arbres (RIMA) au sein du Service canadien des forêts s'intéresse activement aux systèmes d'aide à la décision pour l'obtention de l'information dont elle a besoin pour l'analyse des conditions relatives aux ravageurs forestiers. Le système FIDSINFOBASE a été élaboré afin que les équipes du RIMA dans tout le pays puissent avoir accès aux données des relevés. Des fonctions de systèmes d'information géographique sont intégrées pour la saisie et l'analyse des cartes d'infestation. Il est possible d'intégrer les systèmes, données et modéles de divers organismes pour uniformiser et échanger des données.

Mots-clés: systèmes d'information, gestion des ravageurs forestiers, relevés des insectes et des maladies.

\section{Introduction}

The presence of insects and diseases in the forest is a concern to the forest manager, especially when they cause some form of change. As part of the forest management planning process, information is needed to make effective decisions for managing insects and diseases when they become pests. This information may be on:

- the current state of the forest with regard to insect and disease activity;

- the susceptibility of the forest to infestations;

- the forecasted pest situation for current and subsequent growing seasons;

- recommended control actions:

- the silvicultural and harvesting measures needed to prevent or minimize loss, or to capitalize on a current infestation; and \footnotetext{
'Paper presented at the Joint Technical Session, "Planning the New Forest:
Information Systems". of the Forest Management, Forest Pest Management, and Silviculture \& Tree Improvement Working Groups at the CIF Annual Meeting. St. John's, Nild., August, 1987

2Petawawa National Forestry Institute. Canadian Forestry Service, Chalk River. Ontario. KOJ $1 \mathrm{JO}$
}

- how and where to conduct monitoring and research activities on pest population dynamics, forest stand dynamics, and control.

Decision-making is largely a function of current and potential ways information can be managed. Information access still remains poor, even after technology has permitted an increase in its quality and quantity (Rykiel et al. 1984). When forest managers are faced with a pest problem, they need to use a Decision Support System (DSS) for information assimilation, so that efficient and effective decisions can be made to help alleviate the problem.

This paper describes an existing information system, FIDSINFOBASE, which is being integrated with Geographic Information System (GIS) and statistical analysis tools with a long term goal towards the construction of a DSS (Figure 1). The DSS will provide better analytical capabilities on insect and disease conditions at the federal level of pest management. It may also promote development of systems within provincial and industrial jurisdictions, enabling transfer of these tools to forest managers. These managers will further recognize the importance of pest management in their planning and will be able to formulate effective pest 


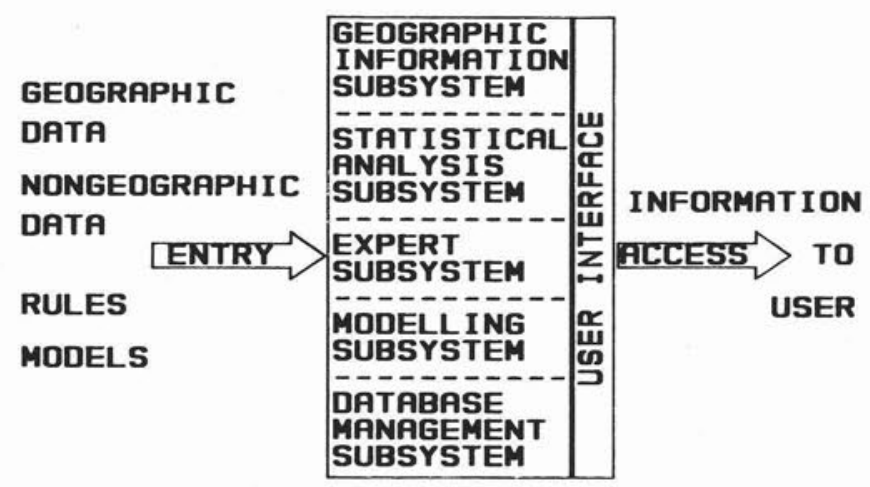

Figure 1. Concept for computer system for forest pest management decision-support.

management decisions upon access to a DSS. Consequently, errors caused by omission of the pest management component in forestry decisions, or by reliance on subjective judgment in pest management issues, will be reduced.

\section{FIDSINFOBASE}

The Forest Insect and Disease Survey (FIDS) of the Canadian Forestry Service (CFS) is responsible for the national surveillance and analysis of forest insect and disease conditions. A major function of the Survey is to provide information for forest pest management decisions. Historically, the Survey has made great efforts to collect data, which became burdensome without tools to manage these data so they can be analyzed. The Survey has reacted to this "hyper-data syndrome" by building a system that can manage and synthesize large amounts of data. The FIDS information system is called FIDSINFOBASE and is described in detail by Power (1986).

The major component of FIDSINFOBASE handles FIDS sampling form data. These are data on site-specific field observations of insects and diseases and associated stand conditions, and corresponding data from laboratory analysis of insect specimens and disease material collected in the field. These data cover all of Canada for surveys undertaken since the late 1930s, comprising over 600000 forms or survey events. All surveys are geographically referenced to $10 \times 10 \mathrm{~km}$ Universal Transverse Mercator grid cells. In support of the survey data are code tables for each data field. The largest and most complex code table is the insect and disease catalogue which lists all of the recognized forest insect and disease species, their codes, and cross-referencing to indicate taxonomic synonymity. Also within the sampling form component are parasite data from laboratory analysis of parasitized insect specimens. All data in the system are analyzed by-FIDS rangers and scientists to describe the presence of pests, their action on the forest, and their trends. They are used in the formulation of a forest insect and disease conditions portfolio for the forest management community.

A special component of FIDSINFOBASE is the Acid Rain National Early Warning System (ARNEWS) ground plot data. The data are used to retain stand, foliar, and soil measurements on a network of permanent plots to detect and identify the cause of change to stand conditions.

There exists much other field survey data in FIDS that can be brought under FIDSINFOBASE. These surveys are for monitoring pest activity and impact on nurseries, plantations, and forest permanent plots, and on insect trap results. Database opportunities are also planned for:

- recording the insect and disease collections located in the herbariums and insectariums of the six CFS regional offices;

- retaining summaries of the national forest inventory for forest depletion estimation exercises;

- capturing forest mortality and growth loss estimates for depletion modelling;

- recording select weather data for ARNEWS-related analysis and for studying weather effects on pest populations; and

- loading pest bulletins and historical and current condition reports as technical and executive information.

FIDSINFOBASE was developed using the INGRES relationa database management system which provides excellent capabilities for applications development, optimal data storage, retrieval, updating, and transaction support. Applications can be quickly prototyped. Modifications and expansions can be done easily without deteriorating system integrity. The system is based at the Petawawa National Forestry Institute, and is accessed through terminals by the six FIDS regional units across the CFS. FIDSINFOBASE provides the capability for data management and the opportunity for development of Decision Support Systems.

\section{Geographic Information Systems}

The management and analysis of map data are handled by Geographic Information Systems. The capabilities offered by these systems are essential in a DSS, to analyze spatial characteristics of the insect- and disease-interactions with the forest and the influencing factors of man and nature.

Throughout the summer months, aerial surveys are conducted by the Survey to sketch-map important pest infestations. The resulting maps are recompiled to create a permanent set of maps, after reconciling with records of infestations of previous years. The areas of infestations are also measured and tabulated. These data are used to obtain an up-to-date regional picture of the location of infestations, and their severity. Past years' maps are used with current year's to derive the overall cumulative effect of successive years of infestation. Projections are made on the next year's activity. The process involves the manual transfer of map data, colouring, dot counting, and overlaying maps on light tables. The application of GIS can automate these functions and provide additional analysis capabilities. Geographic Information System opportunities in FIDS are as follows:

- creation of a national historical database on pest infestations;

- tie-in with forest inventory, weather, and remote sensing data;

- developing models for spatial analysis of one or more themes; and

- integration with FIDSINFOBASE to access data on survey locations.

Utilization of these opportunities will result in improvements of:

- survey design;

- detection and mapping of infestations;

- hazard rating;

- quarantine service;

- analysis of relationships between biophysical factors and pest infestations; 
- estimation of pest-caused forest depletions due to growth loss and mortality;

- prediction of infestations and their impact; and

- research and interpretation of biological and chemical control programs.

Geographic Information System applications in forest pest management have been developed to analyze pest impact on the forest (Morse 1986. Pense et al. 1983), and to develop a system of stand vulnerability (MacLean 1985). Geographic Information System technology is being integrated into FIDSINFOBASE using both the mini- and microcomputer versions of the ESRI Ltd. ARC/INFO system.

An excellent example of a GIS/database application for FIDS operations is being demonstrated in a pilot study on national pest depletion estimation. Composite maps of defoliation by intensity, and mortality, are produced in the GIS from a number of years of surveys. These are reclassified to indicate a level of impact severity for a 5-year-period. The host species volumes that are encompassed by each severity class are obtained through overlaying these classes on the national forest inventory geographic grid to determine grid coverage, and using this to extract the appropriate inventory data from national inventory files. Estimates of depleted volume are calculated by dividing the inventory by factors which estimate a) the frequency of stands impacted within the mapped infestation, and b) the expected portion of the total volume lost to mortality or unrealized growth, both over the 5 year period. These factors are generated by FIDS and other CFS scientists, and reflect their knowledge and understanding, with field data support wherever possible, of the cumulative impact of a pest on a host tree species by cover type over a period of time. This exercise may lead to depletion modelling and a more formal process of archiving the knowledge of experienced entomologists and pathologists, in quantitative terms, for retention in a database.

\section{Expert Systems}

An important feature of the DSS concept is the ability to create and use a knowledge base. "Expert Systems" can be used to store knowledge of pest management of experts in this discipline. This knowledge, which consists of facts and opinions in the form of rules, can be processed by programs in a manner similar to human reasoning to derive possible solutions to complex pest management problems. The acquisition of knowledge by a manager so that he or she may be considered an expert certainly takes time. Ten years must pass before one acquires 50000 entities of information in a particular field of expertise (Hancock 1987). The assistance of expert systems to obtain knowledge, and use of this knowledge by those who have not yet achieved expert status, is of great value to decision-making. Expert systems are useful components in a DSS because they make models accessible and interpretable to non-users. They also take on the functions of a model (Stone et al. 1986).

In pest management, expert systems have been demonstrated in the United States for diagnosis of pest problems in red pine (Pinus resinosa Ait.) stands (Schmoldt and Martin 1986) and to assist in insect taxonomy (Stone et al. 1986). In Finland, a system has been developed to diagnose about 100 insect and disease pests and predict their future activity. Further, the management of over 80 insect defoliators of 140 tree species in North America will be assisted by the application of a system under development in the U.S. ${ }^{3}$

3UFRO S6.02 Working Party Newsletters, April and August, 1987

\section{The Future Outlook}

The FIDSINFOBASE system is approaching what may be termed as a "management information system" (MIS), as it is designed to work with operations that are highly structured. However, management information systems improve the efficiency, but not necessarily the effectiveness, of decisionmaking (Keen and Morton 1978). Decision-support systems have a direct effect on management decisions because they support rather than replace managerial judgment. In the DSS approach, the "structural" and "judgmental" parts of key decisions to a task are identified. The structural parts can then be automated through information access and modelling. Many managers have viewed tasks to be totally judgmental when, in fact, part or all of the task may be structured. Decision Support System development heavily involves managers' input so that the decision-making process is well understood. The inclusion of the human element is important as system failures have incurred with MIS, in particular when the realities of management have not been considered (Keen and Morton 1978).

In forest pest management, DSS concepts are part of systems development in the Integrated Pest Impact Assessment System (White 1986), and for the Southern Pine Beetle system (Rykiel et al. 1984). In these systems, a frontend program would direct the user to the appropriate database and model components. The models that can be based on pest population dynamics, forest stand dynamics, and impact enable the user to develop real or hypothetical pest management scenarios, act on actual problems, or improve one's skills to deal with future problems.

The DSS approach is well-suited to directing the development of FIDSINFOBASE. In the concept, as shown in Figure 1, the strength of database management, GIS, expert systems, and statistical analysis systems such as SAS, would be integrated and linked with databases and models. Each of these subsystems would handle a specific set of functions in capturing, storing, and processing data and models. An intelligent user interface would accommodate users at varying degrees of skill to direct the user to system components that would best support his or her task.

FIDSINFOBASE operations serve a specific purpose within the mandate of FIDS, but its ability to function should be of interst to others who have roles in pest management in Canada. As provincial forestry agencies are already planning the development of information systems for pest management, as demonstrated in British Columbia (Sutton et al. 1985), cooperation between all agencies will have its benefits. If future systems can be compatible, then information can be shared which can only boost the overall system ability to support managers' decisions. Commonality could exist among data definitions and structures, computer tools and communications, models and concepts. This approach may be equated to a similar interagency effort for cooperation on data, models, and systems for Eastern Spruce Budworm (CFS 1979). A renewed effort among forest pest management agencies will provide the opportunity to cooperatively develop the necessary Decision Support Systems.

\section{References}

Canadian Forestry Service. 1979. Report of the task force for the review of Canadian Forestry Service research program on the eastern spruce budworm. Env. Can., Can. For. Serv., Ottawa, Ont.

Hancock, B. 1987. Expert Systems. DEC Professional. 6(5): 40-48. 
Keen, P.W.G., and M.S. Scott Morton, 1978. Decision support systems - and organizational perspective. Addison-Wesley Publ. Co.

MacLean, D.A. 1985. Effects of spruce budworm outbreaks on forest growth and yield. Pages 148-175 in Sanders, C.J.; Stark. R.W.; Mullins, E.J.; Murphy, J., (eds.). Recent advances in spruce budworms research. Proc. CANUSA Spruce Budworms Research Symp., 16-20 Sept., 1984, Bangor, Me. Can. For. Serv., Ottawa, Ont.

Morse, B.S. 1986. Forecasting forest pest hazard with a geographic information system. Pages 255-262 in Proc. Geographic Inf Syst. Workshop. Amer. Soc. Photogrammetry and Remote Sensing, April 1-4, 1986. Atlanta, Ga.

Pense, R., W.M. Ciesla and D.O. Hunter. 1983. Geographic information systems - a computer-assisted approach to managing pest data. USDA Forest Serv., Forest Pest Manag. Methods and Application Group, Fort Collins, CO. Rep. No. $84-1$

Power, J.M. 1986. FIDSINFOBASE - the Forest Insect and Disease Survey information system Can. For. Serv., Petawawa Nat. For. Inst. Inf. Rep. PI-X-65.
Rykiel, E.J., M.C. Saunders, T.L. Wagner, D.K. Loh, R.H. Turnbow, L.C. Hu, P.E. Pulley and R.N. Coulson. 1984. Computer-aided decision making and information accessing in pest management systems with emphasis on the southern pine beetle, Dendroctonus frontalis (Coleoptera: Scolytidae). J. Econ. Entomol. 77: 1073-1082.

Schmoldt, D.L. and G.L. Martin. 1986. Expert systems in forestry utilizing information and expertise for decision making. Computer and Electronics in Agriculture 1:233-250

Stone, N.D., R.N. Coulson, R.E. Frisbie and D.K. Loh. 1986. Expert systems in entomology: three approaches to problem solving. Bull. Ent. Soc. Amer., Fall: 161-166.

Sutton, R.C., P.M. Wood, T.L. Shore and R.D. Cozens. 1985. Report of the task force on a forest pest management information system for British Columbia. BC Forest Serv., Forest Protection Branch, Victoria, B.C.

White, W.B. 1986. Modelling forest pest impacts - aided by a geographic information system in a decision support system framework. Pages 238-248 in Proc. Geographic Inf. Syst. Workshop, Amer. Soc. Photogrammetry and Remote Sensing, April 1-4, 1986. Atlanta, Ga.

\section{Executive Director}

\section{Canadian Forestry Association Association forestière canadienne}

The Canadian Forestry Association is seeking a successor to the Executive Director on his retirement this July. The Canadian Forestry Association is a federation of 9 autonomous Provincial Forestry Associations which seeks to develop public understanding, co-operation and commitment to the wise use, sustainable development and stewardship of Canada's forests and related resources of land, water and wildlife. Since its founding in 1900, the Canadian Forestry Association, in addition to ongoing programs of education and awareness, has served as a "voice of reason" in forestry issues and has been a significant catalyst in the development of sound forest policy.

\section{The Position}

Reporting to the President, the Executive Director is the Chief Operating Officer of the Association and responsible for the program of activities and business affairs of the Association in accordance with policies and procedures established by the Board of Directors. As such, the Executive Director will function as the Treasurer, Secretary and Program Manager.

\section{Qualifications}

An in-depth understanding of forestry, and general knowledge of the workings and inter-relationships of the forestry sector are required. Marketing ability, communication skills and a facility to motivate others are essential attributes for this position.

Experience in association management and/or out of school education is an asset.

Facility in both official languages is desirable.

\section{Terms}

Terms of employment, salary and benefits are negotiable.

For Additional Details Please Contact: (prior to May 30,1988)

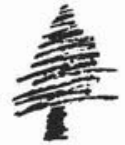
W.K. Fullerton, R.P.F. President,

Canadian Forestry Association,

185 Somerset Street West, Suite 203 , Ottawa, Ontario K2P 0J2

Telephone: (613) 232-1815 